\section{Ekure E.N \\ Esezobor CI \\ Balogun MR \\ Mukhtar-Yola M \\ Ojo $\mathrm{OO}$ \\ Emodi IJ \\ Omoigberale AI \\ Oviawe 0 \\ Ezechukwu CC \\ Olowu AO \\ Ogala WN \\ Esangbedo DO}

\title{
Mothers and childhood pneumonia: what should the focus of public campaigns be?
}

DOI:http://dx.doi.org/10.4314/njp.v40i1.4

Accepted: 30th July 2012

Ekure E.N
Esezobor CI
Department of Paediatrics,

Balogun M R

Department of Community Health and Primary Care

College of Medicine, University of Lagos, Lagos University Teaching Hospital, Lagos, Nigeria.

Email: ekaekure@yahoo.com

Mukhtar-Yola M

Department of Paediatrics, National

Hospital, Abuja

Ojo OO

Lagoon Hospital, Lagos

Emodi IJ

Department of Paediatrics, University of Nigeria Teaching Hospital, Enugu, Nigeria

Omoigberale AI, Oviawe O

Department of Paediatrics, University of Benin Teaching Hospital, Benin City, Nigeria

Ezechukwu CC

Department of Paediatrics, Nnamdi Azikiwe University Teaching Hospital, Nnewi, Nigeria

Ogala WN

Department of Paediatrics, Ahmadu Bello University Teaching Hospital, Zaria, Nigeria
Olowu AO

Department of Paediatrics, Ogun State Teaching Hospital, Sagamu. Nigeria.

Esangbedo D.O

Paediatric Unit, Providence Hospital, Lagos, Nigeria

Abstract Background: Prompt administration of antibiotics to children with pneumonia significantly reduces the probability of death. However this requires early identification of such children in the community. In a country such as Nigeria with one of the highest pneumoniarelated deaths, what do mothers know about pneumonia, and what should be the content of public campaign messages?

Methods: A structured questionnaire was administered to mothers attending paediatric clinics of Lagos University Teaching Hospital seeking their knowledge about the definition, causes, risk factors and symptoms of childhood pneumonia.

Results: One hundred and seven (107) consecutive mothers participated in the study. The majority $(97$; $90.6 \%)$ had at least secondary education, were married $(96 ; 89.7 \%)$ and professed to be either Christians or Muslims (105; 98.1\%).
Prior to the study, 16 (15\%) had not heard about pneumonia. About half of the participants correctly identified fast/difficult breathing as suggestive of pneumonia. Threequarters reported exposure to cold as the cause of childhood pneumonia. Minimizing exposure to cold and wearing warm clothes were the two commonest reported ways of preventing pneumonia $(75.8 \%$ and $49.5 \%$ of the mothers respectively); in contrast hand washing, exclusive breastfeeding and limiting exposure to sick persons with cough and catarrh were the least mentioned. The proportion of mothers who correctly identified fast/difficult breathing as suggestive of pneumonia was similar irrespective of educational status or source of pneumonia information.

Conclusion: Mothers' knowledge of childhood pneumonia is low. Public campaigns on pneumonia should focus on raising awareness about germs as cause of pneumonia, immunization, hand washing and exclusive breastfeeding as potent preventive strategies and fast/difficult breathing as a feature of pneumonia. 


\section{Introduction}

Pneumonia is one of the leading causes of childhood mortality worldwide, with the burden highest in developing countries such as Nigeria. ${ }^{1}$ Fortunately, immunizations against Streptococcus pneumoniae and Haemophilus influenza, the two commonest causes of severe pneumonia, have made huge reduction in pneumonia morbidity and mortality. ${ }^{23}$ However, these vaccines are not universally available with significant non-coverage in regions of the world where pneumonia-related deaths are the greatest. ${ }^{34}$

Even after a child has developed pneumonia prompt institution of appropriate therapies including antibiotics significantly reduce the probability of death. ${ }^{5}$ However such a child with pneumonia needs to be identified at home as sick and needing prompt medical attention. ${ }^{6}$ Therefore if the caregiver fails to realise the immediacy of medical treatment for a child with pneumonia the child may not be brought to the attention of health practitioner and is consequently at risk of a worse outcome. ${ }^{7}$ The early recognition of the features of pneumonia by the caregiver at home is more so important in malariaendemic regions like Nigeria where family-initiated treatment of febrile illnesses as malaria is encouraged, with potential delays in bringing the child to the attention of health care providers. ${ }^{78}$

Previous studies from developing regions of the world where the burden of pneumonia is high have documented that mothers' knowledge of the common features of pneumonia is low. ${ }^{9-11}$ As part of a programme of events during the year 2011 World Pneumonia Day, the Paediatric Association of Nigeria (PAN) undertook the present study to document mothers' knowledge about the common features, major risk factors and causes of childhood pneumonia. The findings of the study would guide the development of campaign resources for public enlightenment about community acquired childhood pneumonia.

\section{Subjects and Methods}

Throughout the second week in November 2011, mothers of children attending the Immunoprophylaxis and Well baby Clinics of the Lagos University Teaching Hospital (LUTH) were invited to participate in the study. Lagos University Teaching Hospital is a feepaying, public-funded tertiary hospital located in Lagos. It provides all levels of care, including primary care, to the residents of Lagos state and neighbouring states. After obtaining informed consent each caregiver was administered a structured questionnaire eliciting their knowledge and care seeking behaviour about community acquired childhood pneumonia. The section on knowledge of pneumonia had questions on definition of pneumonia, risk factors and causes of pneumonia and symptoms suggestive of pneumonia. Others were ques- tions on ways of preventing pneumonia. Each respondent was asked what they would do if their child had pneumonia. To improve completion rate each question (except the question on age of caregiver) had multiple choices and caregivers were encouraged to choose as many correct options as possible for each question. For the caregivers who could not read in English the questionnaire was administered to them by one of the investigators.

The socio-demographic features of the subjects were presented as proportions or as mean (SD). With multiple options per question the number of respondents who chose an option was summarized as a proportion of the total number of possible responses. Characteristics of groups were compared using Chi Square (or Fisher's exact test) or student $t$ test as appropriate. A p value less than 0.05 was considered statistically significant.

\section{Results \\ Demographics of the study participants}

A hundred and seven (107) consecutive caregivers, all mothers, participated in the study. The majority (97; $90.6 \%$ ) of the participants had secondary or post secondary school education, were married $(96 ; 89.7 \%)$ and belonged to the two major religions of Christianity and Islam $(105 ; 98.1 \%)$. Over half $(57.9 \%)$ were of the Yoruba ethnic group while $31(29 \%)$ belonged to the Ibo ethnic group (Table 1).

\begin{tabular}{ll}
\hline \multicolumn{2}{l}{ Table 1: Socio-demographics of Participants } \\
Characteristics of Respondents & $\mathrm{n}(\%)$ \\
\hline Marital Status & \\
$\quad$ Married & $96(89.7)$ \\
Single & $8(7.5)$ \\
Separated/Widowed & $3(2.8)$ \\
Religion & \\
Christianity & $73(64.2)$ \\
Islam & $32(29.9)$ \\
Others & $2(1.9)$ \\
Tribe & \\
Yoruba & $62(57.9)$ \\
Ibo & $31(29.0)$ \\
Hausa & $1(0.9)$ \\
Others & $13(12.1)$ \\
Level of Education & \\
None/Primary & $10(9.3)$ \\
Secondary & $38(35.5)$ \\
Post secondary & $59(55.1)$ \\
Heard of pneumonia before & \\
Yes & $91(85.0)$ \\
No & $16(15.0)$ \\
Sources of information on pneumonia & \\
News Media & $21(23.3)$ \\
Friends/Relatives & $41(45.6)$ \\
Health workers/Facility & $27(30.0)$ \\
Others (e.g. victims, books) & $7(7.8)$ \\
\hline
\end{tabular}

*Total number more than 107 because of multiple responses 
Only $91(85 \%)$ participants reported previously hearing about pneumonia; one of which did not complete the other sections of the questionnaire leaving 90 for analysis. Among those who reported knowledge of pneumonia 'Friends/Relatives' $(41 ; 45.1 \%)$ was the commonest source of information about pneumonia. 'Health workers/Facility' and 'News Media' were reported as the second and third most frequently reported sources of information on pneumonia respectively (Table 1).

\section{Knowledge of what pneumonia is}

Forty eight (53.3\%) participants described pneumonia as infection of the lungs, $17(19.5 \%)$ as cough and catarrh, $17(19.5 \%)$ didn't know while the remainder described it as a cold. (fig 1)

Fig 1: Respondents' knowledge of the definition of pneumonia

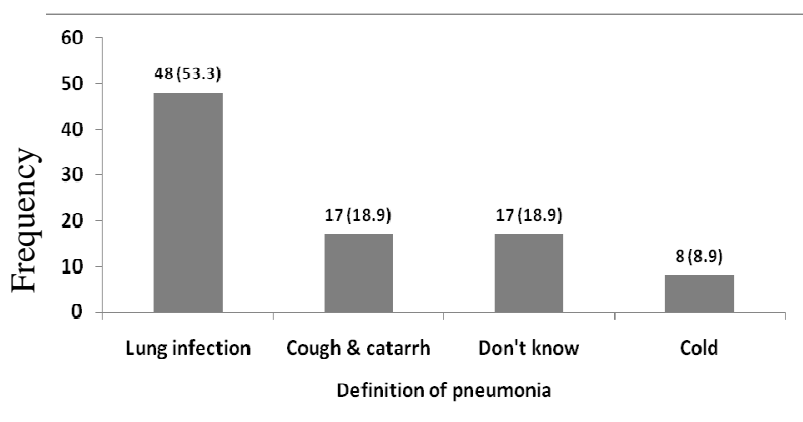

\section{Risk factors and causes of pneumonia}

The majority $(68 ; 74.7 \%)$ of the participants identified exposure to cold as the cause of pneumonia. In contrast only $21(23.1 \%)$ participants chose 'germs' as causes of pneumonia. Concerning the risk factors for childhood pneumonia the two most commonly identified risk factors were 'being under the age of five years' and 'an underlying lung disease'. The two least commonly identified risk factors for pneumonia were 'lack of exclusive breastfeeding' and 'attending a child day care centre' (Fig 2).

Fig 2: Respondents' knowledge of the causes and risk factors of childhood pneumonia

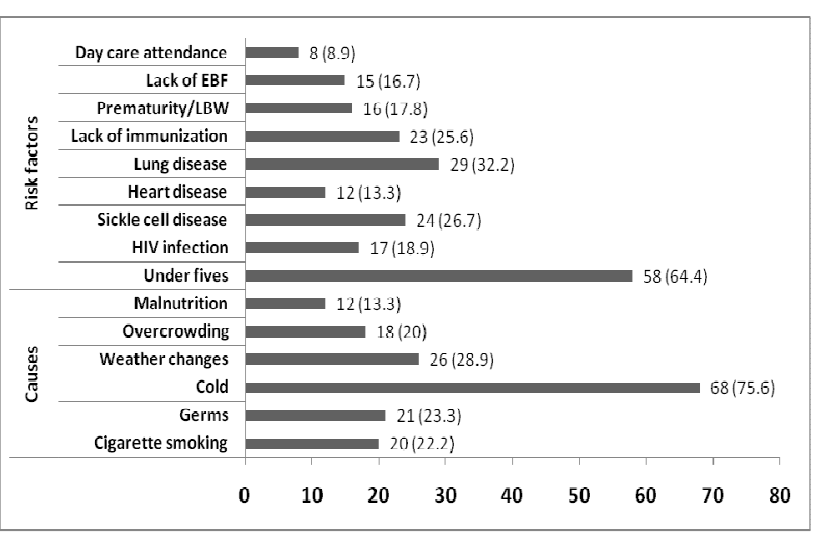

\section{Features of pneumonia}

Over half $(53.8 \%)$ and $42(46.2 \%)$ participants correctly identified 'fast or difficult breathing' and 'fever' respectively as features of a child with pneumonia (Fig 3).

\section{Prevention of pneumonia}

Minimizing exposure to cold $(69 ; 75.8 \%)$ and wearing of warm clothes $(45 ; 49.5 \%)$ were the most frequently reported ways of preventing childhood pneumonia. Limiting exposure to persons with cough and catarrh, hand washing and breastfeeding were the least commonly reported ways of preventing pneumonia. Immunization as a preventive strategy was chosen by 24 (26.4\%) participants (Fig 3).

Except for one, all the participants responded that the correct action to take when a child develops pneumonia is to take the child to the hospital/medical doctors.

Fig 3: Respondents' knowledge of symptoms and ways of preventing pneumonia

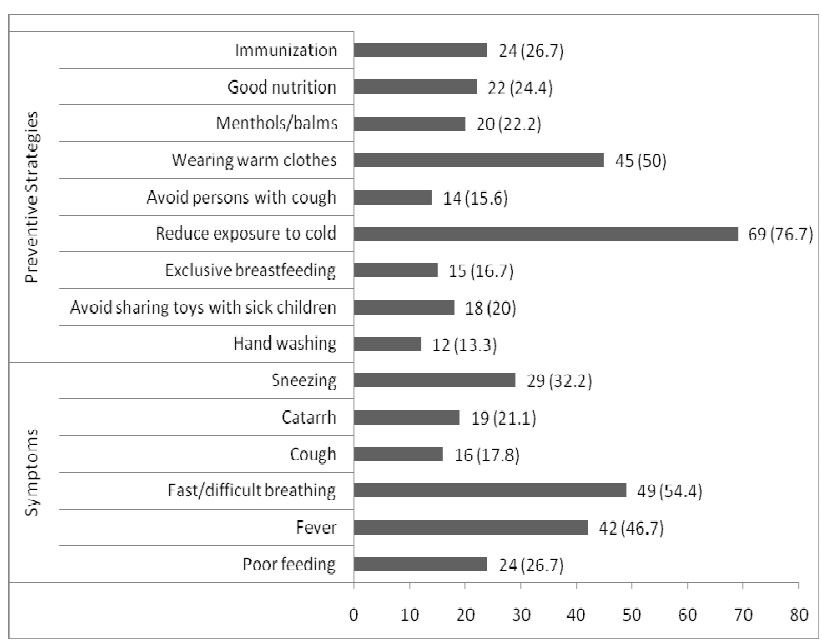

Factors associated with the correct knowledge of pneumonia

Having a post secondary education was associated with correctly identifying pneumonia as an infection of the lungs (64.3\% v $38.2 \%)$ and exclusive breastfeeding as a risk factor $(23.3 \% \mathrm{v} 5.9 \%)$ for pneumonia. Identification of features of pneumonia, germs as cause of pneumonia and other risk factors for pneumonia were similar between participants with post secondary education and those with lower educational level (Table 2). Participants whose source of information on pneumonia was from the news media were more likely to identify exposure to cold as cause of pneumonia. They were also less likely to identify germs as causes of pneumonia though this was not significant $(9.5 \%$ v $29.0 \%$; $=0.069)$ (Table $3)$. Participants who reported health workers/facility as sources of pneumonia information were more likely identify germs as cause of pneumonia $(40.7 \%$ v $17.5 \%)$ and lack of exclusive breastfeeding as a risk factor for childhood pneumonia (33.3\% v 9.5\%) (Table 4). 


\begin{tabular}{llll}
\hline \multicolumn{3}{l}{ Table 2: Correct Responses stratified by Educational Status } \\
$\begin{array}{l}\text { Statements about } \\
\text { pneumonia }\end{array}$ & $\begin{array}{l}\text { Tertiary Education, } \mathrm{n}=90 \\
\text { No }\end{array}$ & P value \\
& $\mathrm{n}=34(\%)$ & $\begin{array}{l}\text { Yes } \\
\mathrm{n}=56(\%)\end{array}$ & \\
\hline $\begin{array}{l}\text { Pneumonia is infection of } \\
\text { the lungs }\end{array}$ & $13(38.2)$ & $36(64.3)$ & 0.016 \\
$\begin{array}{l}\text { Germs are causes of pneu- } \\
\text { monia }\end{array}$ & $7(20.6)$ & $15(26.8)$ & 0.507 \\
$\begin{array}{l}\text { Exposure to cold causes } \\
\text { Pneumonia }\end{array}$ & $27(79.4)$ & $42(75.0)$ & 0.631 \\
$\begin{array}{l}\text { Day Care attendance is a } \\
\text { risk factor }\end{array}$ & $2(5.9)$ & $7(12.5)$ & 0.263 \\
$\begin{array}{l}\text { Lack of EBF is a risk factor } \\
\text { Fast/Difficult breathing is a } \\
\text { feature of pneumonia }\end{array}$ & $2(5.9)$ & $13(23.3)$ & 0.032 \\
$\begin{array}{l}\text { Reducing exposure to cold } \\
\text { prevents pneumonia }\end{array}$ & $22(64.7)$ & $41(73.2)$ & 0.393 \\
$\begin{array}{l}\text { Hand washing prevents } \\
\text { pneumonia }\end{array}$ & $6(17.6)$ & $6(10.7)$ & 0.265 \\
\hline
\end{tabular}

\begin{tabular}{llll}
\hline \multicolumn{3}{l}{ Table 3: Correct Responses stratified by sources of in- } \\
formation on Pneumonia (News Media versus others) \\
$\begin{array}{l}\text { Statements about } \\
\text { pneumonia }\end{array}$ & $\begin{array}{l}\text { Source of information on pneu- } \\
\text { monia, } \mathrm{n}=90\end{array}$ & P value \\
News Media & Other Sources & \\
$\mathrm{n}=21(\%)$ & $\mathrm{n}=69(\%)$ & \\
\hline $\begin{array}{l}\text { Pneumonia is infection of } \\
\text { the lungs }\end{array}$ & $12(57.1)$ & $37(53.6)$ & 0.777 \\
$\begin{array}{l}\text { Germs are causes of pneu- } \\
\text { monia }\end{array}$ & $2(9.5)$ & $20(29.0)$ & 0.069 \\
$\begin{array}{l}\text { Exposure to cold causes } \\
\text { pneumonia }\end{array}$ & $10(47.6)$ & $11(15.9)$ & 0.004 \\
$\begin{array}{l}\text { Day care attendance is a } \\
\text { risk factor }\end{array}$ & $2(9.5)$ & $7(10.1)$ & 0.650 \\
$\begin{array}{l}\text { Lack of EBF is a risk } \\
\text { factor }\end{array}$ & $3(14.3)$ & $12(17.4)$ & 0.517 \\
$\begin{array}{l}\text { Fast/Difficult breathing is } \\
\text { a feature of pneumonia }\end{array}$ & $11(52.4)$ & $43(62.3)$ & 0.416 \\
$\begin{array}{l}\text { Reducing exposure to cold } \\
\text { prevents pneumonia }\end{array}$ & $6(28.6)$ & $21(30.4)$ & 0.870 \\
$\begin{array}{l}\text { Hand washing prevents } \\
\text { pneumonia }\end{array}$ & $1(4.8)$ & $11(15.9)$ & 0.172 \\
\hline
\end{tabular}

\begin{tabular}{|c|c|c|c|}
\hline \multirow{4}{*}{ Questions } & \multirow{2}{*}{\multicolumn{2}{|c|}{$\begin{array}{l}\text { Source of Information on } \\
\text { Pneumonia, } n=90\end{array}$}} & \multirow{4}{*}{$\begin{array}{l}P \\
\text { value }\end{array}$} \\
\hline & & & \\
\hline & Health & Other & \\
\hline & $\begin{array}{l}\text { Workers } \\
\mathrm{n}=27(\%)\end{array}$ & $\begin{array}{l}\text { Sources } \\
\mathrm{n}=63(\%)\end{array}$ & \\
\hline $\begin{array}{l}\text { Pneumonia is infection of the } \\
\text { lungs }\end{array}$ & $15(55.6)$ & $34(54.0)$ & 0.890 \\
\hline $\begin{array}{l}\text { Germs are causes of pneu- } \\
\text { monia }\end{array}$ & $11(40.7)$ & $11(17.5)$ & 0.019 \\
\hline $\begin{array}{l}\text { Exposure to cold causes } \\
\text { pneumonia }\end{array}$ & $7(25.9)$ & $14(22.2)$ & 0.703 \\
\hline $\begin{array}{l}\text { Day care attendance is a risk } \\
\text { factor }\end{array}$ & $5(18.5)$ & $4(6.3)$ & 0.087 \\
\hline Lack of EBF is a risk factor & $9(33.3)$ & $6(9.5)$ & 0.008 \\
\hline $\begin{array}{l}\text { Fast/Difficult breathing is a } \\
\text { feature of pneumonia }\end{array}$ & $15(55.6)$ & 39 (61.9) & 0.573 \\
\hline $\begin{array}{l}\text { Reducing exposure to cold } \\
\text { prevents pneumonia }\end{array}$ & $12(44.4)$ & $15(23.8)$ & 0.050 \\
\hline $\begin{array}{l}\text { Hand washing prevents } \\
\text { pneumonia }\end{array}$ & $6(22.2)$ & $6(9.5)$ & 0.102 \\
\hline
\end{tabular}

\section{Discussion}

Correct and early identification of a child with pneumonia at home allows for prompt referral to health facilities where administration of appropriate antibiotics increases the probability of a better outcome. This strategy of reducing pneumonia deaths takes a greater significance in developing countries such as Nigeria where potent vaccines against Streptococcus pneumoniae and Haemophilus influenza are not routinely available. ${ }^{34}$ These observations underlined the conduct of the present study which documented that the correct knowledge about causes, features, risk factors and strategies of preventing community acquired childhood pneumonia is low among mothers.

With pneumonia among the three biggest killers of children in Nigeria it came as a surprise that only about half of the mothers who reported ever hearing of pneumonia correctly identified pneumonia as an infection of the lungs. Moreover, $15 \%$ of the participants had never heard of pneumonia. Similar, and in some cases, poorer results have been documented from other regions of the world, especially when study populations were from rural areas. ${ }^{610}$ These findings argue for more intense public enlightenment campaigns about pneumonia such as those for measles and malaria that have largely succeeded in creating huge awareness.

Fast and or difficult breathing as a cardinal feature of pneumonia was only reported by about half of the respondents in the present study; with the likelihood that in the other half children with fast/difficult breathing may not be identified as having pneumonia and referred to a healthcare provider. This finding is similar to the report of another study from an urban centre in Nigeria. ${ }^{12}$ In general most studies from developing countries such as Ethiopia, Pakistan and Honduras are unanimous that mothers do not recognize the features of pneumonia such as fast/difficult breathing. ${ }^{91013}$ Because cases of childhood community-acquired pneumonia are commonly preceded by nasopharyngeal infection (common cold) which only requires supportive care at home, failure to recognize fast/difficult breathing as a complication of common cold requiring prompt medical attention has been associated with increased morbidity and mortality from pneumonia. ${ }^{7}$ The ability of caregivers to recognize fast/difficult breathing as a trigger for self referral assumes additional implication in malaria-endemic countries where home management of malaria is advocated. ${ }^{78}$ Because fever is a common feature of both pneumonia and malaria it becomes more important for caregivers to recognize that the presence of fast/difficult breathing in a child with fever should prompt referral to a health facility in order to prevent significant morbidity and mortality. ${ }^{8}$ Results from pneumonia campaigns from different regions of the world have demonstrated significant improvement in pneumonia deaths when messages emphasize the need for prompt referral to the health facility when children develop fast or difficult breathing. ${ }^{511}$ With almost all the respondents in the present study correctly reporting that they will take their child 
with suspected pneumonia to the hospital/doctor, campaigns aimed at teaching them how to recognize this feature of pneumonia are likely to result in fewer deaths from pneumonia.

Fewer mothers in the present study knew the causes of pneumonia and its common risk factors. Similar to most pneumonia surveys world wide exposure to cold and change in weather were the commonly cited causes for pneumonia by mothers. ${ }^{111314}$ This reflects the widely held public view that pneumonia results from exposure to cold air. This view has been reported among Peruvian, Pakistani and Nigerian mothers and explains why mothers employ warmth producing measures as treatment for pneumonia. ${ }^{101115}$ In the present study reducing exposure to cold, wearing of warm clothes and use of heat producing balms such as menthol were the commonly cited strategies to preventing pneumonia. Recognition of germs as the cause of pneumonia was poor in the present study, as in other surveys. ${ }^{11}{ }^{15}$ In the same vein, factors that predispose a child to getting an infection such as lack of exclusive breastfeeding, malnutrition, overcrowding and day care attendance were infrequently mentioned by the vast majority of the respondents in the present study. Not surprisingly the importance of immunization and hand washing as potent strategies in preventing pneumonia was not appreciated. These measures, including exclusive breastfeeding, need to be emphasized in campaign messages because they have been demonstrated to have huge impact on pneumonia-related morbidities and mortalities. ${ }^{23} 1617$

Respondents with less than tertiary education were less likely to have the correct knowledge about some aspects of pneumonia. Two areas where they were less knowledgeable than the respondents with tertiary education were in the recognition that lack of exclusive breastfeeding as a risk factor for pneumonia and the definition of pneumonia. Importantly, fast/difficult breathing was recognized equally by both groups as suggestive of pneumonia. In a country with low illiteracy rate such as Nigeria this finding may allay fears that campaigns emphasizing fast/difficult breathing as trigger for early referral may be ineffective. Our results suggest that such campaigns should be driven by healthcare practitioners, with an additional need to improve the knowledge of the media practitioners about childhood pneumonia. It is not uncommon in Nigeria to find articles in the media emphasizing the need to keep warm as a way of preventing pneumonia. And our findings lend some support to this; respondents with the news media as source of information on pneumonia were more likely to report exposure to cold and not germs as a cause of pneumonia. In contrast those who cited health care workers as sources of pneumonia information identified germs as causes of pneumonia and lack of EBF as a risk factor. With the news media as an effective means of public enlightenment there is a need to target the media practitioners as part of campaigns to improve knowledge of childhood pneumonia and reduce pneumonia -related deaths. Our findings also suggest that the pneumonia campaigns should not be targeted at mothers only, but at the general population because 'friends/relatives' was the commonest source of information on pneumonia.

Our study has some limitations. We studied mothers attending the hospital rather than in the community, hence our sample may not be representative of the general population and may have explained the higher proportion with the correct knowledge and care-seeking behaviour about childhood pneumonia in the present study. Some of the respondents had the questionnaire read to them because they could not read, and this could have introduced some bias; however, the majority of these respondents had not heard of pneumonia before the study and therefore had minimal effect on the study because they were excluded from subsequent analysis.

\section{Conclusion}

Knowledge of fast/difficult breathing as a cardinal feature of pneumonia is modest among Nigerian mothers. Knowledge of cause, risk factors and family-level preventive strategies of pneumonia is even lower. Pneumonia campaign messages should target the general population, and not mothers only, emphasize the recognition of fast/difficult breathing and the need for prompt referral of children with fast/difficult breathing to an appropriate healthcare provider

Authors' contributions: All the authors except ECI and
BMR conceived the study.
EEN and BMR drafted the proposal.
ECI and EEN collected and analysed the data
All authors reviewed and approved the final manuscript
Conflict of Interest: None.
Funding: None

\section{Acknowledgement}

Paediatrics Association of Nigeria gratefully acknowledges the funding support from the International Vaccine Access Centre (IVAC) of Johns Hopkins University Bloomberg School of Public Health for the 2011 World Pneumonia Day celebration and this research. We also appreciate the assistance of Emmanuel John in data entry. 


\section{Reference}

1. Black RE, Cousens S, Johnson HL, Lawn JE, Rudan I, Bassani DG, et al. Global, regional, and national causes of child mortality in 2008: a systematic analysis. Lancet 2010;375(9730):1969-87.

2. Kellner JD, Church DL, MacDonald J, Tyrrell GJ, Scheifele D. Progress in the prevention of pneumococcal infection. CMAJ 2005;173(10):1149-51.

3 . Progress in introduction of pneumococcal conjugate vaccine-worldwide, 2000-2008. MMWR Morb Mortal Wkly Rep 2008;57 (42): 1148-51.

4. Johnson HL, Deloria-Knoll M, Levine OS, Stoszek SK, Freimanis Hance L, Reithinger R, et al. Systematic evaluation of serotypes causing invasive pneumococcal disease among children under five: the pneumococcal global serotype project. PLoS Med 2010;7(10).

5. Sazawal S, Black RE. Effect of pneumonia case management on mortality in neonates, infants, and preschool children: a metaanalysis of community-based trials. Lancet Infect Dis 2003;3 (9):547-56.

6. UNICEF/WHO. The forgotten killer of children. 2006.
7. Kallander K, Hildenwall $\mathrm{H}$, Waiswa P, Galiwango E, Peterson S, Pariyo G. Delayed care seeking for fatal pneumonia in children aged under five years in Uganda: a case-series study. Bull World Health Organ 2008;86(5):332-8.

8. Kallander K, Nsungwa-Sabiiti J, Peterson S. Symptom overlap for malaria and pneumonia--policy implications for home management strategies. Acta Trop 2004;90 (2):211-4.

9. Muhe L. Mothers' perceptions of signs and symptoms of acute respiratory infections in their children and their assessment of severity in an urban community of Ethiopia. Ann Trop Paediatr 1996;16(2):129 -35 .

10. Kundi MZ, Anjum M, Mull DS, Mull JD. Maternal perceptions of pneumonia and pneumonia signs in Pakistani children. Soc Sci Med 1993;37(5):649-60.

11. Galvez CA, Modeste N, Lee JW, Betancourt H, Wilkins RL. Peruvian mothers' knowledge and recognition of pneumonia in children under 5 years of age. Rev Panam Salud Publica 2002;11(2):99-108.

12. Uwaezuoke SN, Emodi IJ, Ibe BC. Maternal perception of pneumonia in children: a health facility survey in Enugu, eastern Nigeria. Ann Trop Paediatr 2002;22(3):281-5.
13. Hudelson PM. The management of acute respiratory infections in Honduras: a field test of the Focused Ethnographic Study (FES). Med Anthropol 1994;15(4):43546.

14. Hudelson P, Huanca T, Charaly D, Cirpa V. Ethnographic studies of ARI in Bolivia and their use by the national ARI programme. Soc Sci Med 1995;41(12):1677-83.

15. Iyun BF, Tomson G. Acute respiratory infections--mothers' perceptions of etiology and treatment in south-western Nigeria. Soc Sci Med 1996;42(3):437-45.

16. Luby SP, Halder AK. Associations among handwashing indicators, wealth, and symptoms of childhood respiratory illness in urban Bangladesh. Trop Med Int Health 2008;13(6):835-44.

17. Niessen LW, ten Hove A, Hilderink $\mathrm{H}$, Weber M, Mulholland K, Ezzati M. Comparative impact assessment of child pneumonia interventions. Bull World Health Organ 2009;87(6):472-80. 